\title{
Tumor markers and kinetics in prostate cancer: a mini-review
}

\author{
Farooq Ahmad Ganie ${ }^{1}$, Mohd Lateef Wani ${ }^{1}$, Shadab Nabi Wani ${ }^{1}$, Mohd Saleem Wani ${ }^{2}$, Ab Gani \\ Ahangar ${ }^{1}$, Shabir Ahmad Ganie ${ }^{2}$, Nasir-ud-din Wani ${ }^{1}$, Mubasher Ahmad Bhat ${ }^{3}$ \\ 1. Department Of CVTS, SKIMS Srinagar, India. 2. Department of Urology, SKIMS Srinagar, India. 3. Department of \\ Anesthesia, SKIMS Srinagar, India
}

Correspondence: Mohd Lateef Wani. Address: Department Of CVTS, Quarter No C9, SKIMS Srinagar, India. Telephone: 941-903-9737. Fax: 01-954-220-737. E-mail: latifs_dr@yahoo.com

Received: J une 3, 2012

DOI : $10.5430 /$ jst.v2n4p57
Accepted: July 9, 2012

URL: http://dx.doi.org/10.5430/jst.v2n4p57

\section{Abstract}

The discovery and utilization of tumor markers have affected early detection, diagnosis, and staging and follow up of Prostate cancer and have improved curative rates. The goal of identifying different tumor markers in prostate cancer is to get the early diagnosis. One can also see the effect of treatment modality used and prognosticate the disease. In this review we intend to give a detailed account of different markers in prostate cancer. Besides Prostate Specific Antigen, Human kallikrein 2, Kallikrein-related peptidase 14, Prostate acid phosphatase, Cancer Antigen 15-3, Prostate-specific membrane antigen etc. are discussed in detail.

\section{Key words}

Prostate cancer, Serum prostate specific antigen, Kallikreins

\section{I ntroduction}

Prostate cancer is the most common form of cancer in man worldwide (followed closely by lung cancer) and the second leading cancer of cancer deaths. It is estimated that more than 3,000,000 new cases are detected every year in United States, of which approximately 41,000 are proved to be lethal ${ }^{[1]}$. There are even more frequent anatomic forms of prostate cancer in which the microscopic focus of cancer is discovered as an incidental finding either at postmortem examination or in surgical specimen removed for other reasons (e.g. prostate nodular hyperplasia). Approximately $90 \%$ of these lesions do not cause trouble during lifetime since prostate cancer is a slow growing tumor ${ }^{[2]}$. Mortality due to prostate cancer has decreased every year since 1992. Though, exact pathogenesis is not clear. Epidemiological evidence supports a relationship between prostate cancer and serum levels of testosterone ${ }^{[3]}$. The risk factors include advanced age, family history, African-American ethnicity, poor diet, and cadmium exposure ${ }^{[4]}$. Strategies for decreasing prostate cancer mortality have focused on early detection.The discovery of tumor markers has made a revolution in the diagnosis and arrangement of benign and malignant diseases of the prostate.

Prostate specific antigen (PSA) is a serine protease produced by benign and malignant Prostate tissue. It is the most notable marker of prostate cancer. Although PSA lacks many of the qualities of an ideal tumor marker, it is still the most widely used marker in the diagnosis and follow-up of Prostate cancer ${ }^{[5,6]}$. Credit for the discovery of PSA is surrounded by 
controversy. The discovery of PSA resulted from the combined effort of numerous eminent scientists searching for antigen in the prostate and in semen (in the late 1960's and early 1970's) with a rapid progress in the field of immunology.With improved biochemical techniques, antigens were being discovered in various tissues and body fluids ${ }^{[7,8]}$. Although the antigens were isolated from several organs, the prostate caught the attention of scientists only in the late 1960's. Paradoxically, more research was dedicated to characterize various antigenic proteins of human semen ${ }^{[9,10]}$.The identification of these antigens independently in prostate tissue and human semen led to them being assigned different names. With the discovery of these antigens (Table 1) subsequent research has shown these proteins to be similar in structure to PSA.

Table 1. The chronology of the discovery of PSA

\begin{tabular}{lll}
\hline Year & Person & Discovery \\
\hline 1960 & Rubin H.Flocks & Species-specific prostate antigens \\
1964 & Mitsuwo Hara & Unique antigen in semen \\
1970 & Richard J.Ablin & Prostate specific antigen r-seminoprotein \\
1973 & Tienshemli & Purification of E1-antigen \\
1978 & George Sensabugh & P30 \\
1979 & Migi Wong & Prostate antigen from prostate tissue \\
1980 & Laurence Papsidaro & Prostate specific antigen from blood \\
\hline
\end{tabular}

A PSA value of $4.0 \mathrm{ng} / \mathrm{ml}$ has been used as the upper limit of the normal, although few studies showed that in $12-23 \%$ of men who had PSA levels between 2.5 and $3.5 \mathrm{ng} / \mathrm{ml}$ prostate cancer was later formed ${ }^{[11,12]}$.It is recommended that the test should be repeated. There are efforts to improve the specificity of the test. Several suggestions have been made but none seems to be ideal. Using age-specific reference ranges with lower threshold for biopsy in younger men and higher in older men can be helpful in deciding who to investigate (Table 2) ${ }^{[13]}$.

Table 2. Age-specific reference ranges

\begin{tabular}{ll}
\hline Age in years & Recommended references in $\mathbf{~ g} / \mathbf{m l}$ \\
\hline$<40$ & $0.0-1.4 \mathrm{ng} / \mathrm{ml}$ \\
$40-49$ & $0.0-2.5 \mathrm{ng} / \mathrm{ml}$ \\
$50-59$ & $0.0-3.5 \mathrm{ng} / \mathrm{ml}$ \\
$60-69$ & $0.0-4.5 \mathrm{ng} / \mathrm{ml}$ \\
$70-79$ & $0.0-6.5 \mathrm{ng} / \mathrm{ml}$ \\
\hline
\end{tabular}

PSA in blood is found both as free PSA and as PSA-complex. For some unknown reason, patients with prostate cancer have lower levels of free PSA than those with benign Prostate hypertrophy and this fact can be used to help improve the diagnosis of prostate cancer ${ }^{[14,15]}$. It has been postulated that patients with a ratio of free to total PSA of greater than $25 \%$ do not require biopsy. However, using this cut off would still miss approximately $8 \%$ of Prostate cancers.

The interval between testing is also in question, as many men are nowadays being tested annually. Recent analysis suggests that testing every two years is adequate, although testing might begin at an earlier age and stop at the age of 75 or even 65 in men with persistently low levels of PSA $(0.5 \text { to } 1.0 \mathrm{ng} / \mathrm{ml})^{[15]}$. 
Table 3. Cut off thresholds of free prostate specific antigen

\begin{tabular}{|c|c|c|c|c|c|c|c|}
\hline $\begin{array}{l}\text { Author (yr) } \\
\text { Assay }\end{array}$ & $\mathbf{N}$ & $\begin{array}{l}\text { TPSArange } \\
\mathrm{ng} / \mathrm{ml}\end{array}$ & ROC/PSA & $\begin{array}{l}\text { ROC \% and } \\
\text { PSA }\end{array}$ & $\begin{array}{l}\text { \%TPSA cut } \\
\text { off }\end{array}$ & Sensitivity & Specificity \% \\
\hline $\begin{array}{l}\text { Partine et al } \\
\text { (1998) Hybritech. }\end{array}$ & 219 & $4-10$ & - & 0,612 & 0.25 & 95 & 20 \\
\hline $\begin{array}{l}\text { Horninger (2000) } \\
\text { Delphia }\end{array}$ & 308 & $2.5-10$ & - & - & 0.20 & 100 & 55 \\
\hline $\begin{array}{l}\text { Veltri and Miller } \\
\text { (1979) Tosoh }\end{array}$ & 531 & $2-20$ & 0,579 & 0,727 & $\begin{array}{l}0,21 \\
0,31\end{array}$ & $\begin{array}{l}0,25(89) \\
0,35(90)\end{array}$ & $\begin{array}{l}30 \\
10\end{array}$ \\
\hline
\end{tabular}

PSA: Prostate specific antigen

TPSA total PSA

ROC: Receiver operating characteristic

\%PSA: Percentage of free PSA

Over the past few years, PSA kinetics have played an increasingly salient role in predicting survival and response to therapy in various disease states in the natural history of Prostate cancer.

\section{PSA-density}

The majority of men over 80years have serum levels in the range of 4 to $10 \mathrm{ng} / \mathrm{ml}^{[16]}$. The most likely reason for the PSA elevation is benign Prostate hyperplasia not Prostate cancer, because of high prevalence of BHP.

Benson and colleagues (1992a, 1992b) introduced a method to correlate more directly the degree with which cancer contributes to serum PSA. One direct relationship between PSA density (PSAD) and the likelihood of cancer has been documented for men with a PSA between 4.0 and $10.0 \mathrm{ng} / \mathrm{ml}$. On normal digital rectal examination, a PSAD greater than 0.15 has been suggested as discriminatory for the presence of Prostate cancer ${ }^{[17]}$. The conflicting results with PSAD have been addressed by Corner (1994). There is a variation in the amount of epithelium (the source of PSA) between prostates of similar size but there is no non-invasive method for determining how much epithelium is contributing to overall PSA. In addition, variability in prostate shape limits the use of common volume equation for calculating prostate size. The major determinant of serum PSA in man without Prostate cancer is the transition zone epithelium, not the epithelium of peripheral zone. Since BHP represents an enlargement of transition zone, thus serum PSA levels are primarily a reflection of transition zone histology in men with BHP. Therefore adjusting PSA for transition zone volume may help in distinguishing between BHP and prostate cancer (Kalish et al 1994). Although not perfect, but still PSAD has remained a useful adjunct in risk assessment of Prostate cancer.

\section{PSA velocity}

Substantial variability and kinetics of serum PSA can occur between measurements in the presence or absence of prostate cancer. PSA-velocity refers to the rate of change of serum PSA. Patients whose serum PSA increases by $0.75 \mathrm{ng} / \mathrm{ml}$ a year are at an increased risk of Prostate cancer. PSA assays should be carried out by the same laboratory over the period of at least 18 months.

PSA doubling time (PSA-DT) is duration of time taken for PSA to double based on an exponential growth pattern. PSA-DT has shown greater promise in smaller retrospective studies on prognostic and predictive indications ${ }^{[18]}$.

PSA-DT can be estimated with two PSA values using the following equation:

$$
\mathrm{Td}=\{\operatorname{In}(2) \mathrm{xt}\} /\{\operatorname{In}(\mathrm{PSA} 1)-\operatorname{In}(\mathrm{PSA} \text { initial })\}
$$


$\mathrm{Td}=31$ days

PSA initial and PSA1 are any two successive PSA values; "t" is the time interval between those values. This is called two-point method for calculating PSA-DT.

Table 4. Definition and Limitations

\begin{tabular}{lll}
\hline PSA derivative & Definition & Limitations \\
\hline PSA density & Serum PSA/prostate volume & $\begin{array}{l}\text { Variations in prostate gland morphology, stromal } \\
\text { to epithelial ratio variations in ultrasound } \\
\text { Volume } \geq 0.15 \quad \text { associated with } \\
\text { measurements } \\
\text { increased risk of prostate carcinoma }\end{array}$ \\
$\begin{array}{l}\text { Variation in assay } \\
\text { The same laboratory } \\
\text { Rate of change of PSA }>0.97 \mathrm{ng} / \mathrm{ml}\end{array}$ \\
\hline
\end{tabular}

Up to 33\% of cancers do not exhibit first-order kinetics in their growth.

\section{Kallikrein tumor markers other than hK3/ PSA}

\subsection{Human kallikrein 2(hK2)}

Human kallikrein $2 \mathrm{hK} 2$ is released in zymogen form from the Prostate epithelium is found in seminal fluid as well as in serum. HK2 and PSA share $80 \%$ amino acid homology. HK2 levels have been shown to regulate PSA activity by activating the zymogen (PPSA) to the active PSA. Through cleavage of amino acid presequence ${ }^{[19]}$, hK2 levels have been shown to be elevated in poorly differentiated prostate cancer.

Human tissue kallikreins hK2, which are encoded by the largest contiguous cluster of protease genes in human genome, are secreted serine proteases with diverse expression pattern and physiological roles. Although primarily known for their clinical applicability as cancer biomarkers, (they have been shown to promote or inhibit neoplastic progression) they might represent attractive targets for therapeutic intervention.

\subsection{Kallikrein-related peptidase 14 (KLK14)}

Elevated levels of this protein have been demonstrated in prostate cancer tissues compared with normal prostate tissue.

\subsubsection{Prostate acid phosphatase (PAP)}

PAP is normally present only in small amounts in blood, but is formed at higher levels in patients with prostate cancer, mostly if the cancer has spread beyond the prostate. However, blood levels may increase in some benign diseases of prostate gland.

\subsubsection{Cancer antigen 15-3 (CA 15-3)}

CA 15-3 is a nonspecific tumor marker. CA 15-3 is one of the tumor markers that were initially considered specific for some types of tumors but were soon found to be indicative of different types of tumors. Its increase could also present an alarm for Prostate cancer. Its normal value is $<38 / \mathrm{L}$ ).

Carbohydrate antigen CA15-3 as initially identified as an expression of breast cancer cell proliferation, where it possess about $15 \%$. However, it was later detected in other tumors too, such as lung, bowel or prostate tumors ${ }^{[20,21]}$. 


\subsubsection{Prostate-specific membrane antigen (PSMA)}

PSMA, also known as folate hydrolase 1 (FOLH1), is a glycoprotein primarily expressed by normal prostate epithelial cells. It has also been found in central nervous system or intestine during malignancy of prostate. Three alternatively spliced variants of PSMA have been identified; one known as PSM is differentially expressed in normal prostate tissue, benign Prostate hyperplasia (BPH) and prostate cancer. It has been demonstrated that the PSMA: PSM ratio is up-regulated three to six fold in prostate cancer. Compared with BHP (0.76 to 1.6) and normal (0.075-0.45) tissue, it has been found that PSMA levels elevate in 50\% of patients with prostate cancer.

\subsubsection{CA 27-29}

CA27-29 antigen is a monoclonal antibody and is present in the apical surface of normal epithelial cells. It has been documented that CA 27-29 is highly associated with breast cancer, but it seems that its level also increase in prostate cancer. Levels more than 100 limits per $\mathrm{ml}$ are suggestive of Prostate cancer ${ }^{[22]}$.

\subsubsection{CA 50}

Carbohydrate antigen CA 50 is another biochemical tumor marker of Prostate cancer. Many studies have been conducted, which have shown increased levels of CA 50 in $11 \%$ of patients with Prostate cancer ${ }^{\text {[23] }}$.

\section{Conclusion}

Screening for prostate cancer should include multiple tumor markers. Although PSA is useful in the screening other markers should also be considered.

\section{References}

[1] Boring CC et al. Cancer station: CA Cancer J Clin. 1994; 44-7.

[2] Isaacs H et al. Molecular markers of prostate cancer. AMJ Pathol. 1997; 150: 1511.PMid:9137077

[3] Ross RK, Bernstein L et al. 5-alpha reductase activity and risk of prostate cancer among Japanese and US white and black males. Lancet. 1992; 339: 887-9.http://dx.doi.org/10.1016/0140-6736(92)90927-U

[4] Pienta KJ, Esper PS set al. Risk factors for prostate cancer. Ann Intern med. 1993; 118: 793-803.PMid:8470854

[5] Teaham SJ, Klotz LH. Current role of prostate-specific antigen kinetics in managing patients with Prostate cancer. BJU Int. 2006; 97: 451-5.PMid:16469006http://dx.doi.org/10.1111/j.1464-410X.2006.05958.x

[6] Hernamdez J, Hompson IM. Prostate specific antigen a review of validation of the most commonly used cancer biomarker. Cancer. 2004; 101: 894-904.PMid:15329895http://dx.doi.org/10.1002/cncr.20480

[7] Milgrom F, Tuggac ZM, Witebsky E. Organ-specific antigen of liver testicle and pituitary. J.Immunol. 1965; 94: 157-63.PMid:14253514

[8] Edginton TS, Glassock RJ, Watson H, Dixon FJ. Characterization and isolation of specific renal tubular epithelial antigens. J.Immunol. 1967; 99: 1199-210.PMid:4862890

[9] Li TS, Behrman SJ. The sperm and seminal plasma-specific antigen of human semen. FertilSteril 1970; 21:565-73.PMid:4194301

[10] Shulman S, Bronson P. Immunochemical studies on human seminal plasma. The major antigens and their fractionation. J. Reprod. Fertil. 1969; 18: 481-91.http://dx.doi.org/10.1530/jrf.0.0180481

[11] Catalona WJ, Smith DS et al. Prostate carrier detection in men with serum PSA. Concentrations of 2.6 to $4.0 \mathrm{ng} / \mathrm{ml}$ and benign Prostate examination. Enhancement of specificity with free PsA measurement. JAMK. 1997; 277: 1452-1455 (level 3 evidence).

[12] Babaian RJ, Johnton DA, Naccarato W et al. The incidence of prostate cancer in a screening population with serum PSA between 2.5 and 4.0ng/ml: relation to biopsy strategy. J.Urol. 2001; 165: 757-760.http://dx.doi.org/10.1016/S0022-5347(05)66519-6

[13] Oesterling JE et al. Serum Prostate-specific antigen in a community-based population of healthy men. Establishment of specific reference ranges. JAMA. 1993; 270-860.

[14] Djavam B, Zlatta A et al. PSA, PSA-density, PSA density of transition zone free/total PSA ratio and PSA velocity for early detection of prostate cancer in men with serum PSA 2.5 to $4.0 \mathrm{ng} / \mathrm{ml}$.

[15] Carter HB, Landin PK et al. Prostate-specif antigen testing of older men. J.Natl Cancer Inst. 1999 Oct. 20; 91(20): 1733-7.http://dx.doi.org/10.1093/jnci/91.20.1733 
[16] Catalone WJ et al. Use of the percentage of free Prostate-specific antigen to enhance differentiation of prostate cancer from benign Prostate disease: A prospective multicenter clinical trial. JAMA. 1998; 279:

1542-1547.http://dx.doi.org/10.1001/jama.279.19.1542

[17] Seaman et al 1993, Bazinet et al 1994. Prostate cancer tumor marking. Urology. 2002; 59: 208.

[18] Michelle L. Ramı́rez, Eric C. Nelson, Ralph W. deVere White, Primo N. Lara Jr., Christopher P. Evans: Current Applications for Prostate-Specific Antigen Doubling Time. european urology. 2008; 54: 291-302.

[19] Saedi MS, Zhu Z, Marker K, Liu RS, Carpenter PM, Rittenhouse H, Mikolajczyk SD. Human kallikrein 2 (hK2), but not prostate-specific antigen (PSA), rapidly complexes with protease inhibitor 6 (PI-6) released from prostate carcinoma cells. Int $\mathrm{J}$ Cancer. 2001Nov; 94(4): 558-63.PMid:11745444http://dx.doi.org/10.1002/ijc.1501

[20] Sturgeon, C.M., Duffy, M.J., Stenman, U.H., Lilja, H., Brünner, N., Chan, D.W., et al. (2008) National Academy of Clinical Biochemistry Laboratory Medicine Practice Guidelines for use of tumor markers in prostate, colorec- tal, breast and ovarian cancers. Clinical Chemistry, 54, e11-e79. http://dx.doi.org/10.1373/clinchem.2008

[21] SinangChourb, Brian Christopher Mackness, Leslie Ruth Farris, Melisenda Jean McDonaldImproved detection Of the MUC1 cancer antigen CA 15-3 by ALYGNSA fluorimmunoassay. Health. 2011 Aug; 3(8). http://dx.doi.org/10.4236/health.2011.38087

[22] GimM,Mione R, Leon AE etal. Comparison of diagnostic accuracy of CA 27-29 and CA 15-3 in primary breast cancer. Cancer Clin Chem. 1999; 45: 632-7.

[23] A marczynfka,Jkulpa .CA -50 serum levels in patients with prostate cancer. Urology Res. 1990 May; 18(3). 